\title{
CAVILACIÓN LITERARIA A PROPÓSITO DE LA PEDAGOGIZACIÓN DE LAS HUMANIDADES
}

\author{
Roberto Alonso Cardona Ospina \\ Magister en Pedagogía \\ Docente investigador Universidad Santo Tomás-Colombia \\ www.roalcaos.blogspot.com
}

Este ejercicio reflexivo surge en el contexto del seminario permanente que realizamos los profesores del Departamento de Humanidades de la Universidad Santo Tomás de Bucaramanga, Colombia. Ante el interrogante por cuáles son los aportes que hace la literatura para una enseñanza reflexiva de las humanidades surge una cavilación en torno al último ensayo que publicó Mario Vargas Llosa.

Aquí se pretende abrir el debate en torno a las ideas de algunos intelectuales que, por su aporte, se podrían clasificar como elitistas, porque invitan al pensamiento unívoco, depurado, excluyente y exclusivo, aparentemente endilgado a ciertas mentes especiales que se proclaman como referentes y ejemplo de lo que los otros deberían ser. Por el propósito pedagógico de esta reflexión es importante mostrar, también, la necesidad de promover un pensamiento más incluyente, respetuoso de la diferencia, propositivo y esperanzador.

Al hablar de literatura y humanidades resulta significativo proponer una reflexión en torno a las recientes ideas que lanzó al mundo de la cultura, y de las letras, el escritor Mario Vargas Llosa a través de La civilización del espectáculo. La obra, así como tiene lectores que la aplauden, también tiene críticos que la miran con desconfianza por la invitación a pensar que la única cultura válida fue la de antaño, la que se elaboró con los antepasados — que si eran personas sabias y cultivadas intelectualmente- una cultura sólida y trascendente que estaba dedicada a mentes especiales, una oportunidad de oro que ya pasó y no volverá.
En esta última obra, el Nóbel peruano, brilla más por su talante de predicador y pareciera abandonar la creatividad del escribidor de cuentos, novelas y relatos; da la impresión que en este ejercicio se diluye y distrae el pensador al dejarse seducir por el deseo de pontificar. Entre las reacciones que Vargas Llosa ha suscitado, resalto la del pensador mexicano y columnista de El País, Jorge Volpi, quien considera que, con este ejercicio, el Nóbel se suma a la abultada lista de hombres de letras que, hacia el ocaso de sus días, se lamentan por la triste condición de su época. (Volpi, 2012)

Por ello precisa Volpi que,

En La civilización del espectáculo, Vargas Llosa acierta al diagnosticar el final de una era: la de los intelectuales como él. Poco a poco se difuminan nuestras ideas de autoría y propiedad intelectual; ya no existen las fronteras entre la alta cultura y la cultura popular; y, sí, se desdibuja el mundo del libro en papel. Pero, en vez de ver en esta mutación un triunfo de la barbarie, podría entenderse como la oportunidad de definir nuevas relaciones de poder cultural. La solución frente al imperio de la banalidad, que tan minuciosamente describe, no pasa por un regreso al modelo previo de autoridad, sino por el reconocimiento de una libertad que, por vertiginosa, inasible y móvil que nos parezca, se deriva de aquella por la que Vargas Llosa siempre luchó. (Volpi, 2012)

Sencillo señalar a una generación como frívola, pero qué pensarán los jóvenes de hoy sobre estos calificativos que les dan algunas 
personas mayores; qué pensarán las recientes generaciones de comentarios despectivos que hacen los hijos de épocas anteriores, ubicados en otro espacio y otro tiempo. La cultura no desaparece con el caos que los intelectuales avistan por el comportamiento superficial y banal de las generaciones actuales; la cultura, el cultivo, es un concepto tan cambiante como las aguas de Heráclito, no puede ser una definición estática, cerrada a revisiones, actualizaciones, virajes, adaptaciones.

Otro de los críticos de Vargas Llosa, el historiador, sociólogo y periodista peruano, Nelson Manrique, al comentar La civilización del espectáculo, y ante la pregunta por la vigencia de la cultura sostiene que,

el objetivo último de la cultura es crear una trama de significaciones que dé sentido a lo que somos, nuestro lugar en el universo y nuestro quehacer humano. Sostengo que no hay culturas superiores e inferiores porque toda cultura que es capaz de cumplir tales funciones tiene la potencialidad intrínseca de crecer y desarrollarse ilimitadamente. (Manrique, 2012)

Y resalta Manrique que el desarrollo de la cultura es proporcional al desarrollo y las oportunidades económicas de los pueblos y las personas,

No existen culturas superiores e inferiores sino culturas de sociedades ricas y culturas de sociedades pobres. Las culturas que se asientan en la pobreza se desarrollan pobremente, mientras que las culturas sostenidas por una base económica poderosa se desarrollan con gran poder. Removidas las barreras que limitan a las "culturas pobres" estas suelen recuperarse con bastante rapidez. (Manrique, 2012)

La cultura conlleva una apertura comprensiva de lo que cada día deviene a los humanos porque ellos construyen, dinamizan y recrean de manera permanente los ambientes socio- culturales. $Y$ en ese sentido no hay humanos de primera y humanos de segunda, cultos e incultos; las oportunidades que la sociedad, y la misma libertad individual permiten, configuran personas tan distintas que la primera manifestación de la inteligencia, y por ende, de la cultura incluyente, es el reconocimiento y la aceptación de la diferencia.

La cultura, así como los valores, son cambiantes, necesitan adaptarse a los permanentes movimientos de la sociedad y las personas. Resultan más respetuosos de la diversidad y la diferencia aportes como los de Ernesto Sábato en La resistencia donde el argentino hace un llamado a revisar la condición actual de los valores pero a través de un ejercicio esperanzador pues considera que el valor más importante es la misma vida e invita a no deshumanizar lo humano.

Hay un contraste importante entre las ideas de Vargas Llosa y lo que propone el argentino Ernesto Sábato en La resistencia, este último también hace un análisis de la situación actual del mundo de la cultura, y el mundo de los valores, pero con una perspectiva esperanzadora, que no ignora la compleja y desconocida condición humana, e invita a respetar las libertades y las múltiples opciones humanas.

Creo que la libertad nos fue destinada para cumplir una misión en la vida; y sin libertad nada vale la pena. Es más, creo que la libertad que está a nuestro alcance es mayor de la que nos atrevemos a vivir. Basta con leer la historia, esa gran maestra, para ver cuántos caminos ha podido abrir el hombre con sus brazos, cuánto el ser humano ha modificado el curso de los hechos. Con esfuerzo, con amor, con fanatismo. (Sábato, 2003, p. 30)

Como es fácil caer en disertaciones ingenuas, vale la pena también acudir al pensador colombiano, William Ospina, quien es gran defensor de la cultura clásica y, aunque reconoce la poca profundidad del fenómeno cultural 


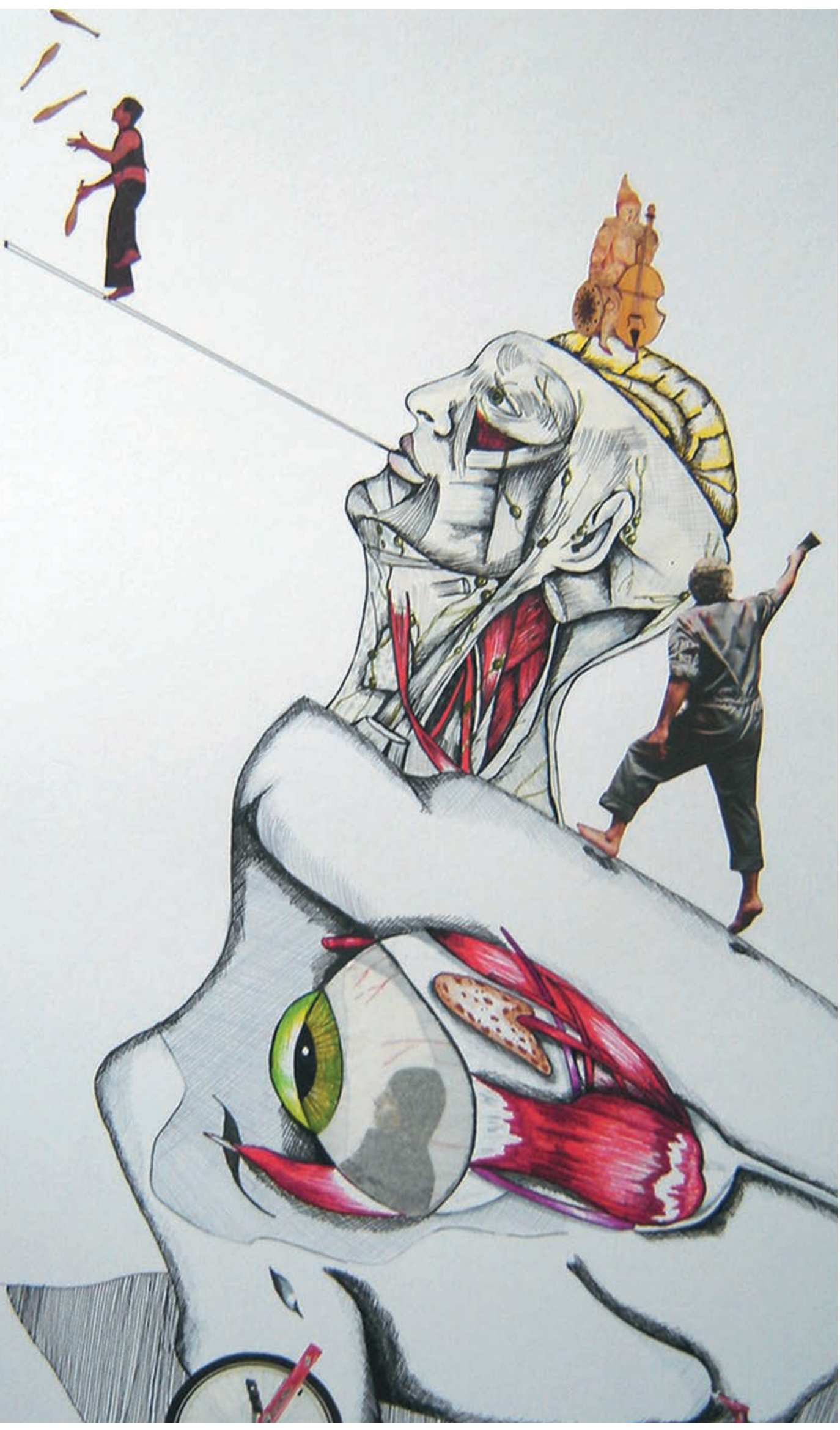




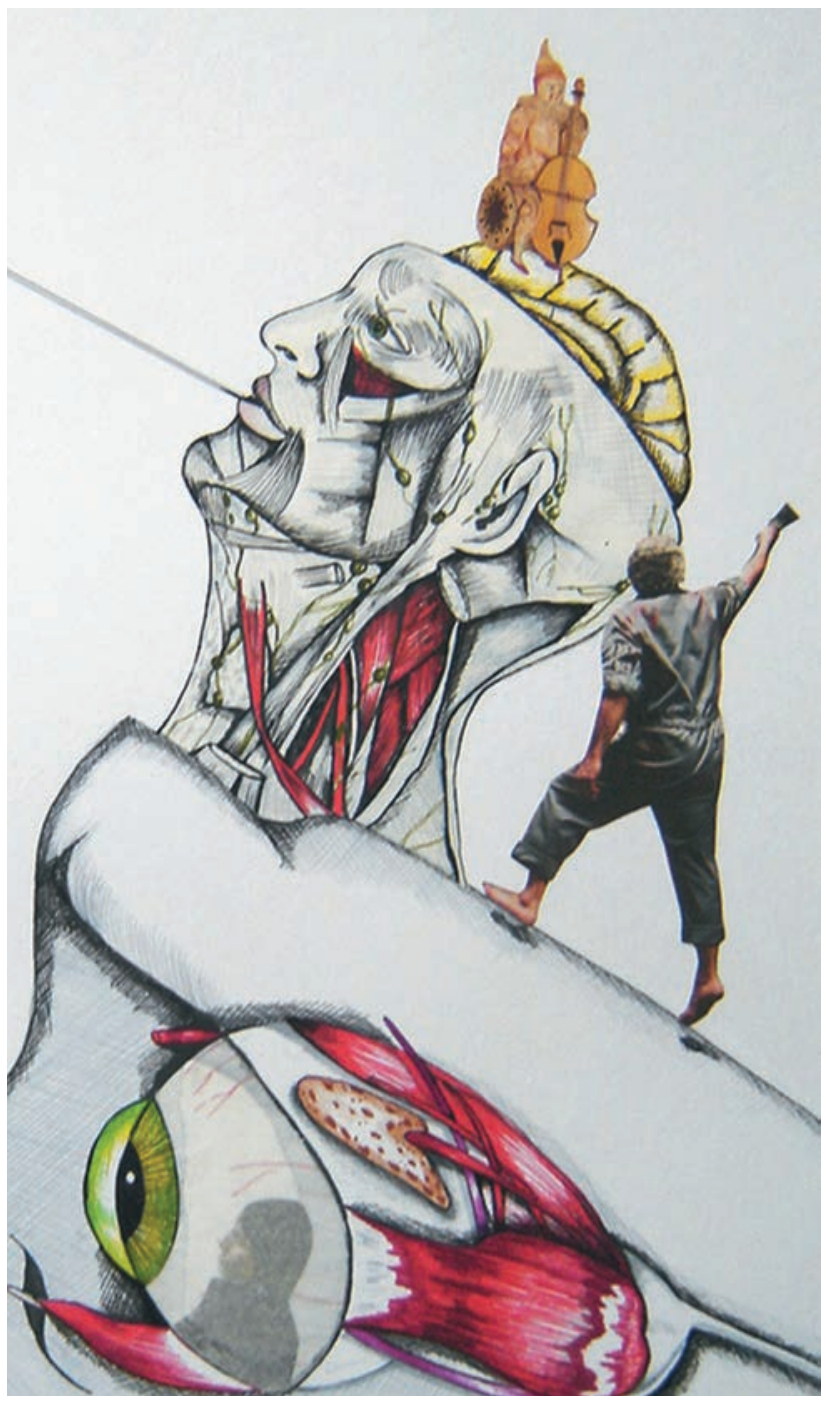

presente, también acota que la situación se presenta porque en la actualidad pasamos por una de las etapas más aceleradas y agitadas de la existencia humana, todo va tan rápido que no alcanzamos a procesar los permanentes cambios,

es verdad que vivimos en una época que a toda prisa cambia costumbres por modas, conocimientos por información, y saberes por rumores, a tal punto que las cosas ya no existen para ser sabidas sino para ser consumidas" (Ospina, 2012, p. 16)

Pero estas manifestaciones socioculturales, artísticas, emotivas, festivas, al sumarse al emparentado tema educativo, pueden dejar cierto desasosiego, pesimismo; por ello el mismo
Ospina, al hablar de cómo algunos piensan que ante la crisis lo mejor es asegurar que la educación ha fracasado, invita a no tenerle miedo a los cambios, porque el ser humano es el único capaz de aprender y sobre todo el único capaz de inventar cosas distintas. (Ospina, 2012, p. 30)

La literatura, como ejercicio creador de nuevos mundos, de mundos de sentido, como opción de mundos posibles, abre un panorama que brinda múltiples iniciativas a los lectores -y por ende a los pedagogos - para promover un ejercicio tolerante y reflexivo que ayude a pensar y debatir sobre el presupuesto de mentes y espíritus respetuosos de la diferencia, con mayor capacidad de adaptación a los permanentes cambios culturales, humanos, sociales, artísticos e intelectuales, a los cambios vitales.

La vida y los seres vivos somos cambiantes, de ahí la importancia de aceptar que los otros y las distintas culturas procesan los valores y la cultura de manera diferente, aceptan y adaptan los desarrollos tecnológicos y demás encuentros al dinámico mundo social. Para permanecer quietos, estáticos, tenemos la eternidad; para cambiar sólo unos pocos años: la corta existencia humana.

\section{BIBLIOGRAFÍA}

Manrique, Nelson (2012) El espectáculo de la civilización III. La República, Perú. Julio 31 de 2012. Disponible en http://www.larepublica.pe/columnistas/ en-construccion/el-espectaculo-de-la-civilizacioniii-31-07-2012 Consultado el 17 de agosto de 2013

Ospina, William (2012) La lámpara maravillosa. Bogotá. Mondadori,

Sábato, Ernesto (2003) La resistencia. Bogotá. Planeta.

Vargas Llosa, Mario (2012) La civilización del espectáculo. Bogotá. Alfaguara.

Volpi, Jorge (2012) Elúltimo de los mohicanos. El País, España. Abril 27 de 2012. Disponible en http://elpais.com/ elpais/2012/04/18/opinion/1334759323_081415. html. Consultado el 17 de agosto de 2013 